\title{
Emerging trend in manufacturing of 3D biomedical components using selective laser sintering: A review
}

\author{
Pankaj Kumar ${ }^{1, *}$, Gazanfar Mustafa Ali syed ${ }^{2}$ \\ ${ }^{1,2}$ Center for Materials and Manufacturing, Department of Mechanical Engineering, S R Engineering College Warangal, India
}

\begin{abstract}
Additive manufacturing (also known as 3D printing) process is an emerging technique for the fabrication of biomedical components. Selective laser sintering or melting is one of the widely used additive printing technology for manufacturing of metallic and non-metallic components used in the industry. This review paper presents, a summary of the published research papers on the fabrication of biomedical components using selective laser sintering technique. Therefore, author meticulously attempted to investigate individual biocompatible material-wise review which includes Ti6Al4V, Ti-7.5 Mo alloy, $\beta$ Ti35Zr28Nb, PEEK, PA2200, and Polyamide/Hydroxyapatite. In addition, this article also explores the effects of the various laser sintering process parameters such as laser power, scanning speed, density of the material on the mechanical properties, tribological properties, porosity and surface roughness of the fabricated alloy. Moreover, the author also investigated challenges and future prospective of the laser processing of biomedical implants.
\end{abstract}

\section{Introduction}

Additive manufacturing is a manufacturing technique where a 3D product is created by adding material in successive layers (as opposed to removing material from a block). There are various types of additive manufacturing state-of-the-art and techniques in the design and development of various 3D components [1, 2]. Recently, researchers are involved in the design and fabrication of improved biomedical implants used in knee and hip joint replacement for Osteoarthritis (OA) patients [3-5]. Osteoarthritis (OA) is a form of degenerative joint pain caused by wear and tear on joints. The soft bone cartilage in the hip, knee and shoulder joints joint wear away over the passage of time and the condition becomes very painful. Hence, there is a need for providing improved biomedical implants that are resistant to any wear and tear. Selective laser sintering (SLS) is one of the additive manufacturing processes for fusion of powder materials to build 3D components using laser power energy. This process is widely used for the fabrication of metal matrix composite for making precision components such as biomedical implants for better tribological and corrosion resistance properties of the fabricated components. Figure 1 shows different steps of selective laser sintering process. Now a day, many research articles have been published which includes design and fabrication of biomedical components such as 3D printing of bone, prosthetics, intervertebral discs, medical equipment, heart valve, etc. using this technique. This review article mainly focused on the research work that has been published on additive manufacturing of 3D biomedical

\footnotetext{
* Corresponding author: pankaj_kumar@,srecwarangal.ac.in
}

components using Ti6Al4V, Ti-7.5 Mo alloy, $\beta$ Ti35Zr28Nb, PEEK, PA2200, and Polyamide/Hydroxyapatite composites.

\section{Selective laser sintering and melting}

\subsection{Selective laser sintering of Ti6Al4V}

The authors [6-8] reported fabrication of 3D metal matrix composite (MMC) used for the implants is fabricated using laser sintering process. In order to enhance the service life of the implant existing implants Ti6Al4V is mixed with the wear-resistant and biocompatible nano $\mathrm{cBN} / \mathrm{TiO}_{2}$ reinforcements. On the basis of good wettability and bonding between Ti6Al4V and $\mathrm{cBN}$, such composition is considered in the present invention. The method comprises fabricating a 3D MMC implant using DMLS (additive manufacturing) process in which a solid body is fabricated layer by layer where the high-intensity laser is scanned over metal powder bed $[9,10]$. This is a laser additive technology for making precise and complex objects. If needed, further optional secondary manufacturing and finishing steps are carried out. Whereas [11] carried investigation on selective melting of Ti6Al4V powder to find out surface roughness and porosity and reported that the fabricated component has an average surface roughness $(\mathrm{Ra})$ of $17.6 \pm 3.7 \mu \mathrm{m}$ and less porosity as compared to the component fabricated through conventional techniques. 


\section{Powder Preparation \\ Preheating \\ Laser Sintering Process \\ 3D Printed Components}

Fig. 1. Different steps of Laser sintering process

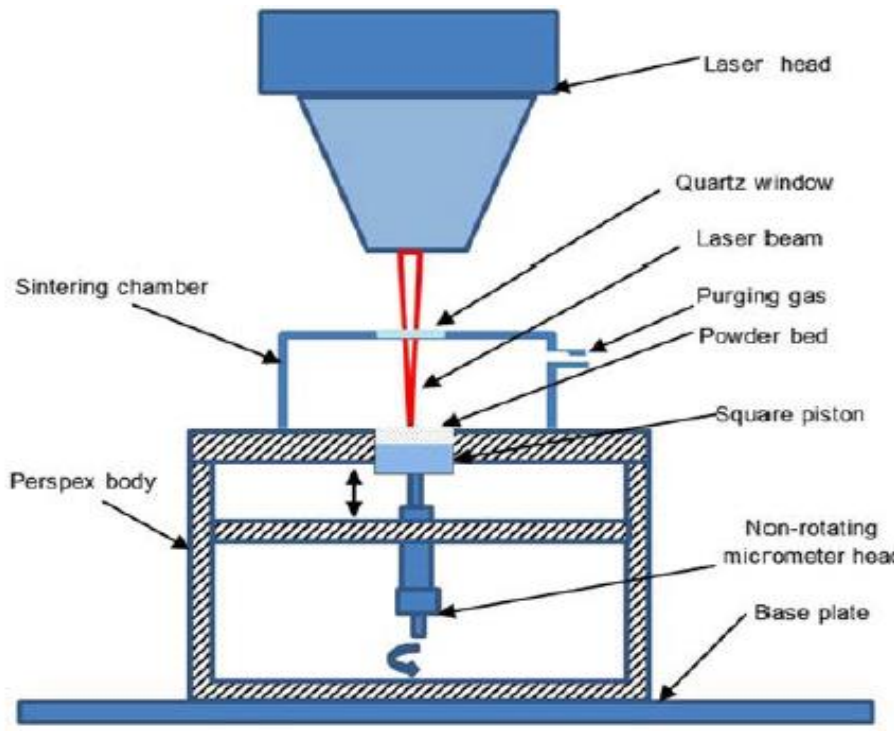

Fig. 2. Schematic representation of the direct laser sintering arrangement [6]

\subsection{Selective laser sintering of Ti-7.5 Mo-alloy}

Recently, researchers around the globe have shown keen interest in fabrication of dental implant and skeletal repair using Titanium foam. Researcher [12] reported preparation porous $\mathrm{Ti}-7.5 \mathrm{Mo}$ alloy from mixed power using the SLS technique. The author has concluded that after the sintering of this material, the pore morphology changes from open to close pores on variation of temperature from 1000 to $1200{ }^{\circ} \mathrm{C}$. Whereas, from the compressive stress-strain curve, it is observed that on decreasing porosity, Elastic modulus and yield strength increases in the range from $3.26-12.7 \mathrm{GPa}$ and 58.6182.5 MPa respectively. Whereas [13] carried out preparation and characterization of high strength and low modulus Ti-7.5Mo from powder mixture using SLS technique. The results of this paper indicate that sintered alloy has a high tensile strength $(>700 \mathrm{MPa})$ and ductility (9\%) with low Young's modulus (70 GPa). However, [14] prepared Ti-Mo alloys using SLS technique and performed a study of its microstructure and tensile properties. The author has reported that the density of the fabricated sample was very high approximately 99 percentages with special conchoidal structure along with $70 \mathrm{GPa}$ and $700 \mathrm{MPa}$ as the modulus and ultimate tensile strength.

\subsection{Selective laser sintering of $\beta-T i 35 Z$ Zr28Nb}

Many researchers $[15,16]$ carried out investigations on fabrication of $\beta-T i 35 \mathrm{Zr} 28 \mathrm{Nb}$ scaffold using SLS technique for a bone implant and reported that the fabricated alloy has excellent biocompatibility with good anti-corrosion properties. The fabricated alloy also exhibits excellent mechanical properties of trabecular bone with the elastic modulus $(0.2-5) \mathrm{GPa}$ and compressive strength (4-70) MPa. Whereas [17-19] performed an experimental investigation on the corrosion behavior of Ti35Zr28 Nb in Hanks' solution at $37^{\circ} \mathrm{C}$ and $3.5 \mathrm{wt} \% \mathrm{NaCl}$ solution at $95^{\circ} \mathrm{C}$. These investigations indicate that there was no evidence of crevice corrosion under various conditions.

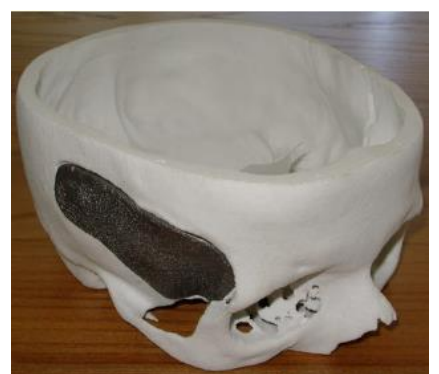

Fig. 3. Custom-made skull plate manufactured in medicalgrade titanium using SLM technology [18]

\subsection{Selective laser sintering of PEEK}

3D Spinal Implants for the future generation can be implemented for old age patients. Because the implant is only designed and developed for a particular patient and surgery, it can be costly to produce as referred to an offthe-shelf implant. Presently modern scientific innovation is involved to improve the physical condition of victim's spines. 3D manufacturing technology enables a health care professional to develop a prosthetic that smoothly fits the anatomy of a patient [20]. For manufacturing medical instruments or implants the best option to use is Polyetheretherketone (PEEK), Such components are usually made using traditional manufacturing processes, such as injection molding. Using Selective Laser Sintering (SLS) can give greater versatility to the components fabricated [21, 22]. However, [23, 24] have performed fabrication of scaffolds of PEEK using SLS technique and reported that the tensile strength and elasticity modulus of CF/PEEK composites higher than injection molded pure PEEK. Whereas, [25] investigated a material which has excellent mechanical, thermal, rheological and chemical properties used in aerospace industries. There are many ways of fabrication of composites using graphene and PEEK which possess all the mentioned properties. However, [26] investigated critical barriers in 3D Printing of PEEK due to the higher temperatures needed for melting, lack of availability of appropriate feedstock, time-consuming, concerns over poor adhesion between layers, and noneconomic processing steps. The author also discussed feasible solutions and mechanisms for the processability of PEEK. Figure 4 shows comparative properties of EOS PEEK HP3 produced using selective lasers sintering against injection molded PEEK 450G and PA2201/PA12. 


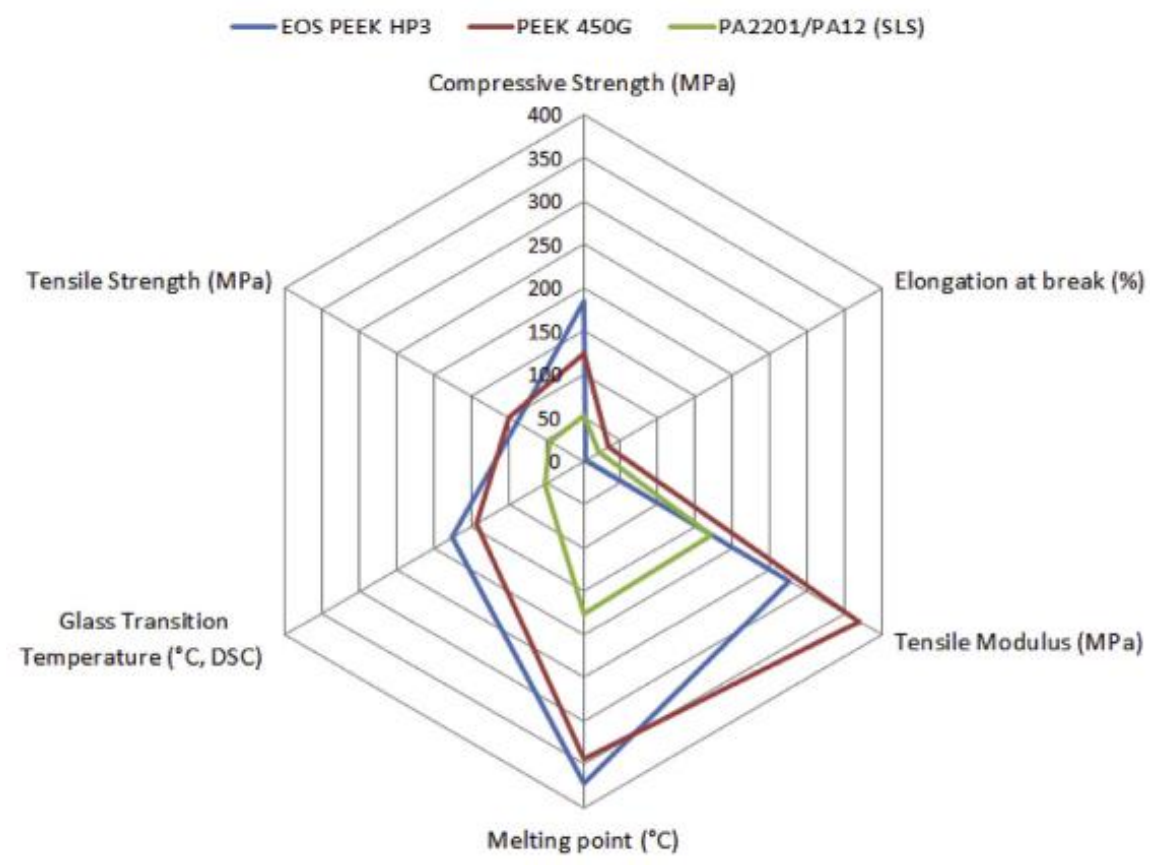

Fig. 4. The comparative properties of EOS PEEK HP3 produced using selective lasers sintering against injection molded PEEK 450G and PA2201/PA12[21]

\subsection{Selective laser sintering of PA2200}

[27,28] carried fabrication of 3D scaffolds made of PA200 using SLS technique and reported that the fabricated polymer scaffold has higher strength. The author has also reported that a differential mechanical property of PA2200 parts can be achieved. Moreover, [29] investigated the effects of the process parameters on the mechanical properties of the PA 2200. Different parameters considered for optimization include orientation, position and preheating temperature. The reported results indicate that the optimal preheating temperature is $170^{\circ}$ for the sample fabricated at $0^{\circ}(\mathrm{Z})$ whereas $171^{\circ} \mathrm{C}$ for the sample fabricated at an inclined angle of $45^{\circ}$.

\subsection{Selective laser sintering}

2.6 Recently a thick bone-like structure, almost identical in appearance and material to the bone is reported [30, 31]. The developed structure can be in dental work, orthopedic applications and also for scaffolding in fractured parts of the body on which new bones may grow [32]. Figure 4 represents effects of laser power density on the porosity of the fabricated material. This material also dissolves when new bone grows in its place, and there will be no harmful effects on the body. The developed methods can be used for the design and fabrication of customized replacement of bone tissue created in this manner.

I) Hydroxyapatite - Hydroxyapatite is a material that is highly biocompatible $[33,34]$. In fact, a modified form of hydroxyapatite constitutes a lot of the composition of the naturally occurring bone. Hydroxyapatite is quite often used to prepare materials for bone grafting and bone repairing [35]. The compressive strength that the material has is anisotropic, a property that bears similarity to human bones. 3D printed hydroxyapatite has structural properties that allow it to bear load and have a high strain $[36,37]$.

II) Hyperelastic bone - Hyperelastic bone is a $3 \mathrm{D}$ printing material, that is primarily composed of bone mineral or hydroxyapatite, along with a biocompatible material like polyglycolic acid [39, 39]. Hyperelastic bone has an extensive lattice structure. It is highly osteoregenerative and easy to utilize in in-vitro and in vivo applications. It is very absorbent, easy to use in surgery and very elastic. However, though it has been tested on animals with promising results, hyperelastic bone has not yet been approved by the FDA for human use.

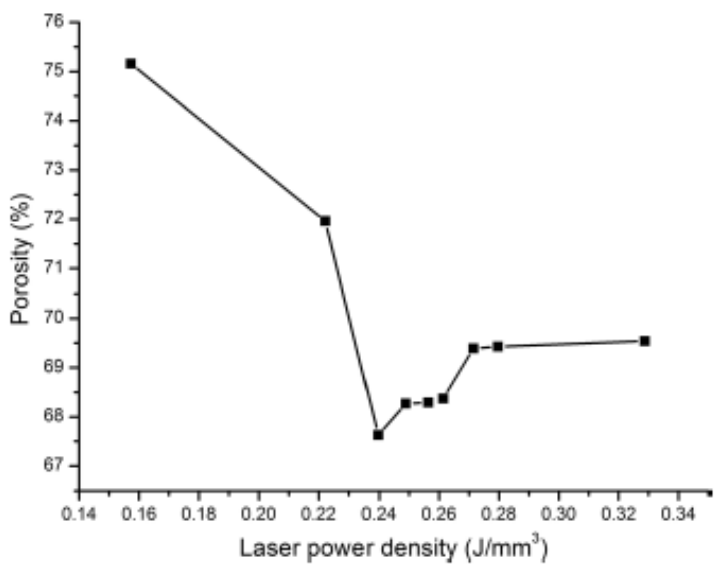

Fig. 5. The relation between the laser power density and the porosity of as-SLS specimens with $10 \mathrm{wt} \% \mathrm{HA}$ [30]

\footnotetext{
* Corresponding author: pankaj_kumar@srecwarangal.ac.in
} 


\section{Challenges and future prospective in laser processing of biomedical implants}

3D printed prosthetics are highly susceptible to durability and easily breakable when pulled wrongly due to produced layer by layer deposition. This technology requires highly skilled professionals for manufacturing and maintaining uniform temperature to decrease the formation of the cracks in the final products. In addition, the 3D printed products should also be tested and approved by the concerned government agency. In addition to this, some of the limitations and challenges of this 3D manufacturing technology also include long manufacturing time and high cost incurred in production.

\section{Conclusions}

In this paper, the author presented a summary of the past and present investigation undergoing in fabrication of biomedical components through laser sintering process. From these literatures, it can be concluded that most of the paper reported laser sintering technique significantly enhances the thermal and tribological properties of the fabricated alloy as compared to other methods. The following points are drawn from the literature review:
- Biomedical components fabricated through laser sintering process exhibit better tribological and mechanical properties

- Composition of the powder is an important factor that can affect the hardness, wear and surface roughness of the fabricated alloy

- This technique enables the development of bonelike structures that can be used for scaffolding, orthopaedic and dental work along with bones for customized replacement.

\section{Recommendations for future work}

The present review paper mainly concentrates on the literatures based on the addition of a single type of reinforced material in them during the preparation of powder for the sintering of alloy. Therefore, further investigation can be performed on hybrid (more than one type of material in the powder sample). In addition to this, the investigation can also be carried out on the effects of the shape and size of the reinforced particle in the base powder on the performance of the biomedical components.

Table 1. Mechanical Properties of the 3D biomedical components manufactured using selective laser sintering

\begin{tabular}{|c|c|c|c|c|c|}
\hline Material & Strength (MPa) & Density & $\begin{array}{c}\text { Surface Roughness (SR)/ } \\
\text { Wear/ Coefficient of } \\
\text { friction (COP) } \\
\end{array}$ & Micro-hardness & Reference \\
\hline \multirow{4}{*}{ Ti6Al4V } & ------ & $4.23 \mathrm{~g} / \mathrm{cm}^{3}$ & Wear: $26.49 \mu \mathrm{m}$ & $519 \mathrm{HV}$ & {$[6]$} \\
\hline & $\begin{array}{ll}----- \\
\end{array}$ & $3.40-4.10 \mathrm{~g} / \mathrm{cm}^{3}$ & COP: $0.33-0.42$ & $388-590 \mathrm{HV}$ & {$[7]$} \\
\hline & & $\begin{array}{c}2.2 \text { to } 2.66 \\
\mathrm{~g} / \mathrm{cm}^{3}\end{array}$ & COP: $0.40-0.50$ & 487-683 HV & {$[8]$} \\
\hline & $\begin{array}{ll}----- \\
\end{array}$ & ------ & SR: $17.6 \pm 3.7 \mu \mathrm{m}$ & $\begin{array}{ll}---- \\
\end{array}$ & {$[11]$} \\
\hline \multirow[b]{2}{*}{ Ti-7.5 Mo-alloy } & $(>700 \mathrm{MPa})$ & $\begin{array}{c}\text { Relative } \\
\text { Density: } 99.7 \%\end{array}$ & ---- & ----- & {$[13]$} \\
\hline & $740 \mathrm{MPa}$ & $\begin{array}{c}\text { Relative } \\
\text { Density: } 85.5 \% \\
\text { to } 99.5 \% \text {. } \\
\end{array}$ & ---- & ----- & {$[14]$} \\
\hline \multirow{2}{*}{$\beta-\mathrm{Ti} 35 \mathrm{Zr} 28 \mathrm{Nb}$} & $\begin{array}{c}\text { Compressive Strength: } \\
4-70 \mathrm{MPa}\end{array}$ & Porosity: $83 \%$ & SR: $4.5 \mu \mathrm{m}$ & ------ & {$[15]$} \\
\hline & $\begin{array}{c}\text { Compressive Strength: } \\
132.5 \pm 3.5 \mathrm{MPa}\end{array}$ & Porosity: $61.1 \%$ & ---- & ------ & {$[16]$} \\
\hline \multirow{5}{*}{ PEEK } & $97 \mathrm{MPa}$ & $1.3 \mathrm{~g} / \mathrm{cm}^{3}$ & ---- & $\begin{array}{ll}----- \\
\end{array}$ & {$[20]$} \\
\hline & $73 \mathrm{MPa}$ & $1.3 \mathrm{~g} / \mathrm{cm}^{3}$ & ---- & ------ & {$[21]$} \\
\hline & $88.7 \pm 1.5 \mathrm{MPa}$ & $1.31 \pm 0.2 \mathrm{~g} / \mathrm{cm}^{3}$ & $\begin{array}{c}\text { Average asperity height: } \\
24.5 \mu \mathrm{m}\end{array}$ & ----- & {$[22]$} \\
\hline & $101.03 \mathrm{MPa}$ & $\begin{array}{c}\text { Volume } \\
\text { fraction: } 31 \%\end{array}$ & ---- & ------ & {$[24]$} \\
\hline & $109 \pm 1 \mathrm{MPa}$ & ---- & $\begin{array}{l}----- \\
\end{array}$ & $\begin{array}{ll}--- \\
\end{array}$ & {$[25]$} \\
\hline \multirow{2}{*}{ PA 2200} & $64.13 \mathrm{MPa}$ & ---- & ------ & ---- & [27] \\
\hline & $48.1 \mathrm{MPa}$ & $0.93 \mathrm{~g} / \mathrm{cm}^{3}$ & ------ & ---- & {$[29]$} \\
\hline \multirow{3}{*}{$\begin{array}{l}\text { Polyamide/ } \\
\text { Hydroxyapatite }\end{array}$} & $\begin{array}{c}\text { Compressive Strength: } \\
26 \mathrm{MPa} \\
\end{array}$ & ----- & ----- & ----- & {$[31]$} \\
\hline & $\begin{array}{c}\text { Compressive Strength : } \\
23.77 \pm 3.34 \mathrm{MPa} \\
\end{array}$ & $\begin{array}{c}\text { Porosity: } 77.36 \\
\%\end{array}$ & ----- & ----- & {$[32]$} \\
\hline & $\begin{array}{c}\text { Compressive Strength: } \\
22 \mathrm{MPa}\end{array}$ & ----- & ----- & ----- & [36] \\
\hline
\end{tabular}




\section{References}

1. L.J. Kumar, C.K. Nair, In Advances in $3 d$ printing \& additive manufacturing technologies (pp. 39-54). Springer, Singapore (2017)

2. Wang, T. Sparks, F. Liou, J. Newkirk, In Laser additive manufacturing (pp. 351-371). Woodhead Publishing (2017)

3. M.L. Sun, Y. Zhang, Y. Peng, D.J. Fu, H.Q. Fan, R. He, Orthopaedic Surgery (2020)

4. B. Qiu, F. Liu, B. Tang, B. Deng, F. Liu, W. Zhu, M. Zhang, J. Knee Surg, 30(08), 822-828 (2017)

5. R. Boorla, T. Prabeena, Mater. Today, 18, 36383642 (2019)

6. M. Hussain, V. Kumar, V. Mandal, P.K. Singh, P. Kumar, A.K. Das, Mater. Manuf. Process., 32(14), 1667-1677 (2017)

7. S. Kundu, M. Hussain, V. Kumar, S. Kumar, A.K. Das, Int. J. Adv. Manuf., 97(5-8), 2635-2646 (2018)

8. S. Misra, M. Hussain, A. Gupta, V. Kumar, S. Kumar, A.K. Das, J. Laser Appl., 31(1), 012005 (2019)

9. M. Hussain, P. Gupta, P. Kumar, A.K. Das, Arab J Sci Eng., 45(2), 1173-1180 (2020)

10. E. Fereiduni, M. Yakout, M. Elbestawi, In Additive Manufacturing of Emerging Materials (pp. 55-109). Springer, Cham (2019)

11. J. Vaithilingam, E. Prina, R.D. Goodridge, R.J. Hague, S. Edmondson, F.R. Rose, S.D. Christie, Mater. Sci., 67, 294-303 (2016)

12. F. Xie, X. He, X. Ji, M. Wu, X. He, X. Qu, Mater. Technol., 32(4), 219-224 (2017)

13. N. Kang, X. Lin, C. Coddet, X. Wen, W. Huang, Mater. Lett., 267, 127544 (2020)

14. N. Kang, Y. Li, X. Lin, E. Feng, W. Huang, J. Alloys Compd., 771, 877-884 (2019)

15. Y. Li, Y. Ding, K. Munir, J. Lin, M. Brandt, A. Atrens, C. Wen, Acta Biomater., 87, 273-284 (2019)

16. W. Xu, J. Tian, Z. Liu, X. Lu, M.D. Hayat, Y. Yan, C. Wen, Mater. Sci., 105, 110015 (2019)

17. J. McElligott, Z. Shi, Y. Li, C. Wen, A. Atrens, Mater. Corros., 69(2), 197-206 (2018)

18. M. Heywood, Z. Shi, Y. Li, C. Wen, J. Kanwar, Y. Xiao, A. Atrens, Mater. Corros., 70(3), 529-536 (2019)

19. A. Mazzoli, Med Biol Eng Comput, 51(3), 245-256 (2013)

20. P. Honigmann, N. Sharma, B. Okolo, U. Popp, B. Msallem, F.M. Thieringer, BioMed research international, (2018)

21. K.M. Rahman, T. Letcher, R. Reese, In ASME 2015 International Mechanical Engineering Congress and Exposition. American Society of Mechanical Engineers Digital Collection (2015)
22. T.J. Hoskins, K.D. Dearn, S.N. Kukureka, Polym. Test., 70, 511-519 (2018)

23. B. Chen, S. Berretta, K. Evans, K. Smith, O. Ghita, Appl. Surf. Sci., 428, 1018-1028 (2018)

24. W. Zhu, C. Yan, Y. Shi, S. Wen, J. Liu, Q. Wei, Y. Sci. Rep., 6, 33780 (2016)

25. M. Yan, X. Tian, G. Peng, D. Li, X. Zhang, Compos Sci Technol, 165, 140-147 (2018)

26. S. Singh, C. Prakash, S. Ramakrishna, European Polymer Journal (2019)

27. C.S. Miron-Borzan, M.C. Dudescu, P. Berce, In MATEC Web of Conferences (Vol. 94, p. 03010). EDP Sciences (2017)

28. J.P. Singh, P.M. Pandey, A.K. Verma, Rapid Prototyping Journal (2016)

29. L.L. Dincă, N.M. Popa, N.L. Milodin, C. Stanca, D. Gheorghiu, In MATEC Web of Conferences (Vol. 299, p. 01001). EDP Sciences (2019)

30. G. Brunello, S. Sivolella, R. Meneghello, L. Ferroni, C. Gardin, A. Piattelli, E. Bressan, Biotechnol. Adv., 34(5), 740-753 (2016)

31. B.I. Oladapo, S.A. Zahedi, A.O.M. Adeoye, Compos. B. Eng., 158, 428-436 (2019)

32. S. XiaoHui, L. Wei, S. PingHui, S. QingYong, W. QingSong, S. YuSheng, L. WenGuang, Int. J. Adv. Manuf., 81(1-4), 15-25 (2015)

33. G.S. Krishnakumar, N. Gostynska, E. Campodoni, M. Dapporto, M. Montesi, S. Panseri, M. Sandri, Mater. Sci., 77, 594-605 (2017)

34. A. Szcześ, L. Hołysz, E. Chibowski, Adv. Colloid Interface Sci, 249, 321-330 (2017)

35. M.A. Nazeer, E. Yilgör, \& I. Yilgör, Carbohydr. Polym., 175, 38-46 (2017)

36. X. Song, H. Tetik, T. Jirakittsonthon, P. Parandoush, G. Yang, D. Lee, D. Lin, Adv. Eng. Mater., 21(1), 1800678 (2019)

37. X. Li, Y. Yuan, L. Liu, Y.S. Leung, Y. Chen, Y. Guo, Y. Chen, Bio-Design Manuf, 3(1), 15-29 (2020)

38. A.E. Jakus, A.L, Rutz, S.W. Jordan, A. Kannan, S.M. Mitchell, C. Yun, R.D. Galiano, Sci. Transl. Med., 8(358), 358ra127-358ra127 (2016)

39. Y.H. Huang, A.E. Jakus, S.W. Jordan, Z. Dumanian, K. Parker, L. Zhao, R.N. Shah, Plast. Reconstr. Surg., 143(5), 1397-1407 (2019) 